\title{
Laboratory field experimental studies of bridge agricultural unit
}

\author{
Bulgakov V. ${ }^{1}$, Adamchuk V. ${ }^{2}$, Kuvachov V. ${ }^{3}$, Holovach I. ${ }^{4}$, Ihnatiev Ye. ${ }^{5}$ \\ ${ }^{1,4}$ National University of Life and Environmental Sciences of Ukraine \\ 15 Heroiv Oborony Str., Kyiv, 03041, Ukraine \\ ${ }^{2}$ National Scientific Center «Institute of Mechanization and Electrification of Agriculture» 11 Vokzalna \\ Str., Hlevakha township, Vasylkiv district, Kyiv region, 08631, Ukraine \\ 3, 5 Dmytro Motornyi Tavria State Agrotechnological University \\ 18 B. Khmelnitskyi, Ave., Melitopol, Zaporizhzhia region, 72312, Ukraine

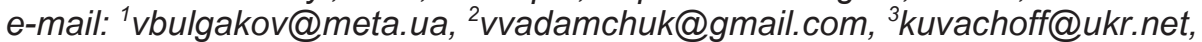 \\ ${ }^{4}$ holovach.iv@gmail.com, ${ }^{5}$ yevhen.ihnatiev@tsatu.edu.ua \\ ORCID: ${ }^{1} 0000-0003-3445-3721,{ }^{2} 0000-0003-0358-7946,{ }^{4} 0000-0003-1387-4789,{ }^{5} 0000-0003-0315-$
}

Goal. To assess the technical implementation and production efficiency of bridge mechanization for the track system of agriculture in the technological processes of tillage and application of technological materials (on the example of an agricultural tool with a developed design). Methods. Experimental studies were performed according to both conventional and developed methods using a modern strain gauge and control measuring equipment with the analog-to-digital conversion of signals from information sensors. Results. According to the results of experimental studies of the bridge agricultural unit as a part of agricultural tools for surface tillage, high adaptability to the implementation of technological processes for tillage has been proved. Comparative graphs are built of normalized correlation functions and normalized spectral densities of profiles of irregularities of traces of a constant technological track and profiles of irregularities of agrophones after the passage of a toothed harrow, as well as a S-shaped spring ripper, and also a rotary harrow. Based on them, it is established that the work of agricultural tools for surface tillage has a good effect on the nature of the non-uniformity of oscillations of their traction resistance. Conclusions. The main generator of the formation of irregularities of the longitudinal profile of the soil traces of the constant technological track is the parameters of the soil hooks of the tires of the wheels of the bridge agricultural unit. The oscillations of the irregularities of the profiles of the treated agrophones by the bridge agricultural unit with attached agricultural tools (S-shaped spring ripper and rotary harrow) are smoother as a result of the movement of the agricultural unit along the compacted traces of a constant technological track. The quality of tillage with units based on bridge agricultural unit is approximately the same as in similar traditional machine-tractor units. But the specific energy consumption per 1 ha of the cultivated area with new units is lower by $40 \%$.

Key words: bridge unit, constant technological track, normalized correlation function, correlationspectral characteristics.

\section{DOI: https://doi.org/10.31073/agrovisnyk202009-06}

Sustainable highly efficient development of track and bridge agriculture [1-6] in the world is possible provided the widespread implementation of scientific and technological progress. At the same time, the problem of finding new tillage implements, machines and tools for their effective use in track and bridge systems of agriculture becomes extremely relevant $[7,8]$. One of the representatives of the family of tillage machines for their use in track and bridge agriculture are agricultural implements for surface tillage. Functional possibilities of their use in technologies of the minimum tillage can provide loosening of a surface layer to its structured condition without removal of moisture on a surface, stability of work of working bodies on depth, high quality of tillage and so on [9].

Analysis of recent research and publications. Scientists from all over the world now make a great contribution to the development and popularization of track and bridge agriculture [8, 10-12]. The materials published by them can be divided into several categories. The first should include problematic articles of a general nature [8], which set out the issues of the issue and outline the main directions of problem solving. In contrast to general publications, in which the problems are approached systematically and do not always take into account the possibility of practical implementation of the proposed solutions, some importance is given to the works whose authors tried to implement bridge units [8]. Creating prototypes of machines encounters all sorts of difficulties, specific models do not always meet all requirements. At the same time, such publications, as a rule, do not sufficiently reflect the results of experimental studies of bridge agricultural units. A special category are copyright certificates and patents for inventions [8, 13-17]. This type of activity does not always give fruitful practical results. Most often, the authors of such patents are far from the practical implementation of their ideas. It often turns out that the ideas of creating new working bodies for bridge and track agriculture are far from reality, and even a cursory analysis reveals their economic or technical failure [8]. In this situation, a detailed analysis of the 
experimental tests of agricultural machinery and implements in the units of track and bridge farming, as well as the practical experience gained is invaluable for science.

Research objective. To assess the technical feasibility and production efficiency of the functioning and use of the bridge facilities for mechanization of agricultural production for the track system of agriculture (on the example of agricultural unit construction developed by us) in the technological processes of processing and introduction of technological materials.

Materials and methods. Experimental studies were conducted using both generally accepted and developed methods. The methodology of experiments provided for the use of modern strain-gauge and control and measuring equipment with analog-digital conversion of signals from information sensors. Processing of experimental data was carried out on PC using probability theory, regression and correlationspectral analysis.

In the process of carrying out the experiments it was supposed to determine the following characteristics: oscillations of longitudinal profile of roughness of traces of constant technological track and roughness of agrophone before and after processing with a bridge unit, soil moisture and density, depth of processing and oscillations of traction resistance of agricultural implements.

Normalized correlation function $\rho(h)$ of the measuring parameters was calculated according to the recommendations [18]:

$$
\rho(h)=\frac{1}{D_{h}(n-m)} \sum_{i=1}^{n-m}\left(h_{i}-m_{h}\right) \cdot\left(h_{i+m}-m_{h}\right),
$$

where $n$-number of measurements;

$m$ - the number of points of the correlation function, $m=0,1,2, \ldots, 10$;

$h_{i}-$ the value of the studied parameter, $i=1, m$;

$m_{h}$ - mathematical expectation of the measuring parameter;

$D_{h}$ - measurement parameter dispersion.

Normalized spectral density of measuring parameters $s(\omega)$ was calculated according to the recommendations $[18,19]$ :

$$
s(\omega)=\frac{\Delta l}{\pi}\left[1+2 \sum_{i=1}^{m} \rho_{i} \cos \left(m_{i} \cdot \Delta \omega\right)\right],
$$

where $\Delta \omega=\frac{\pi}{m \cdot \Delta l}-$ frequency step of the measuring parameter.

The physical objects of research were agricultural units for processing and application of mineral fertilizers, which are built on the basis of the bridge agroforestry construction developed by us (Fig. 1).
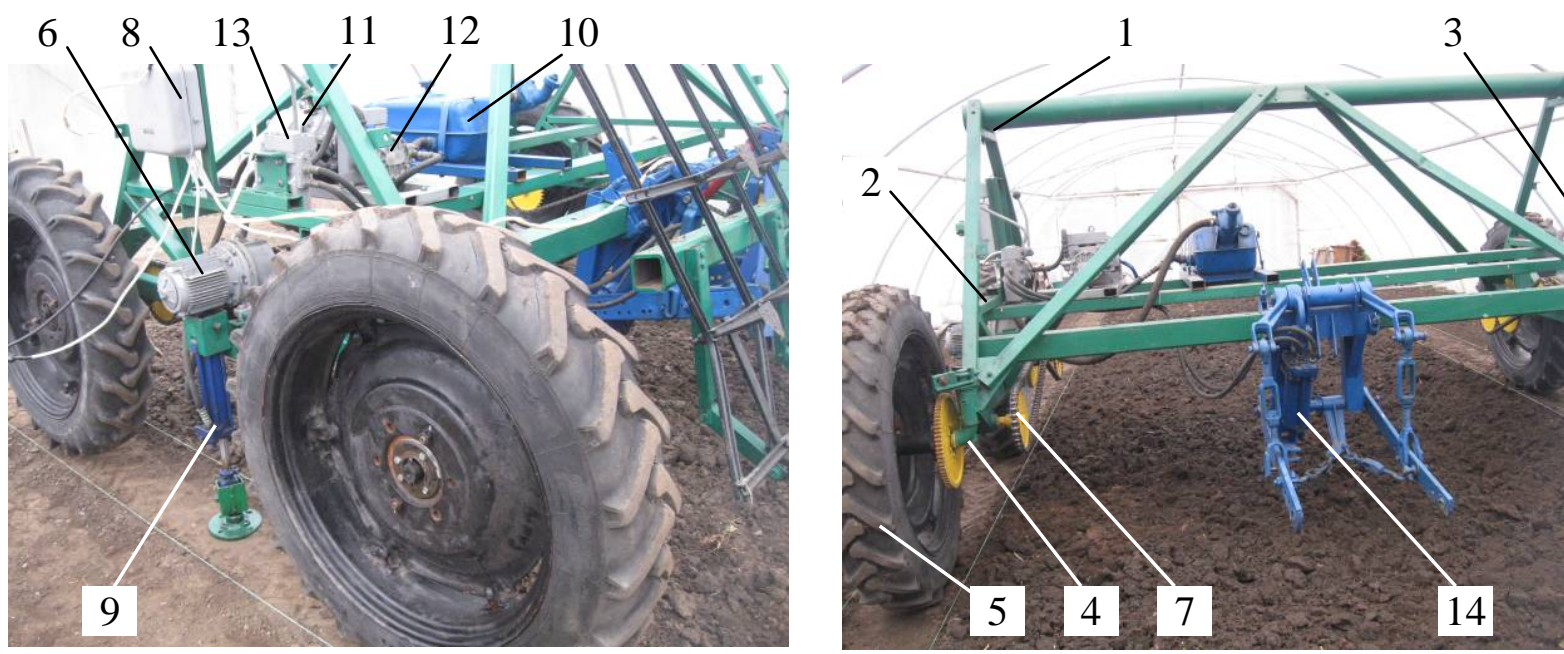

Fig. 1. The structure of the bridge agricultural unit: $a$ - side view; $b$ - rear view

The main technical characteristics of the bridge agricultural unit: Operating weight, $\mathrm{kg}-1158$; Total engine power for wheel drive, $\mathrm{kW}-3,0$; Nominal traction force, $\mathrm{kN}-6,3$; Wheel track width, $\mathrm{m}-3,5$; Longitudinal wheelbase, $m-2,3$; Wheel tires -9,5R32; The way to turn - power (onboard).

The bridge agricultural unit (Fig. 1) contains a power farm 1, which is an agricultural units base frame rigidly connected to the left 2 and right 3 platforms. The brackets 4 with wheels 5 are attached to platforms 2 and 3. Wheel 5 rotation is carried out with the help of two gear motors 6 installed inside platforms 2 and 3, and synchronous mechanisms 7 drive the front and rear wheels 5 from each side of the axle. At the top of the left-hand platform 2 there is a block cabinet 8 with chassis control devices. 
Between the front and rear wheels 5 on the lower surface of platforms 2 and 3 there are support racks of power jacks 9 for lifting the sides of agricultural unit from any side. On bars of a power farm 1 additional units of hydraulic system of agricultural unit are placed, in particular a tank 10 for hydraulic liquids, the electric engine 11 of a drive of the hydraulic pump 12 a hydraulic distributor 13 . Also in the central part of the agricultural unit is located hydraulic hitch 14 , which is borrowed from a serial wheeled tractor traction class 1.4. By means of the hinged mechanism 14, agricultural units and implements are aggregated with the agricultural equipment.

In the course of experimental research, the agricultural unit of this construction was combined with the following agricultural implements:

- tooth harrow (Б3СС-1,0 type) (fig. 2a);

- rotary harrow (fig. $2 \mathrm{~b}$ );

- S-shape scarifier (fig. 2c);

- electric fertilizer spreader (fig. 2d).

Tooth harrows (BZSS-1,0 type) were used as harrowing unit (Fig. 2a) [20]. On the specified harrow on the teeth of the first row in the longitudinal-vertical plane segments are installed, and on the second segments are installed at a greater angle to the horizon than the segments of the last rows. According to the authors of the project, such constructive implementation ensures high quality of soil cultivation. Efficiency and energy intensity of the harrow is of potential interest for its use as part of the bridge units, which function and are used in the track system of agriculture.

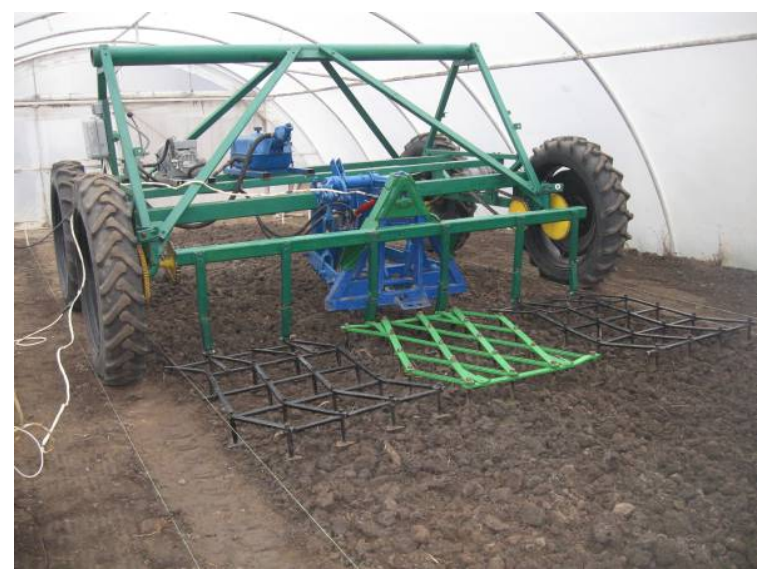

a

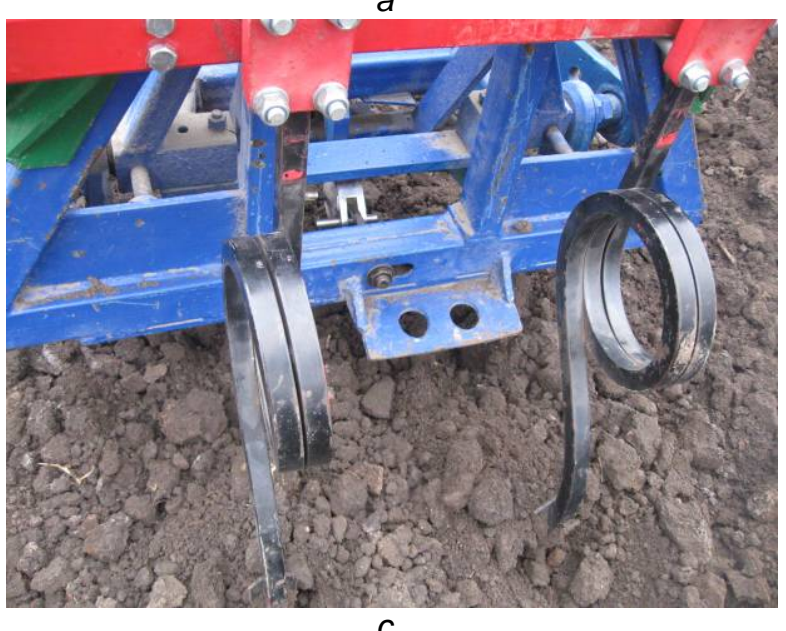

C

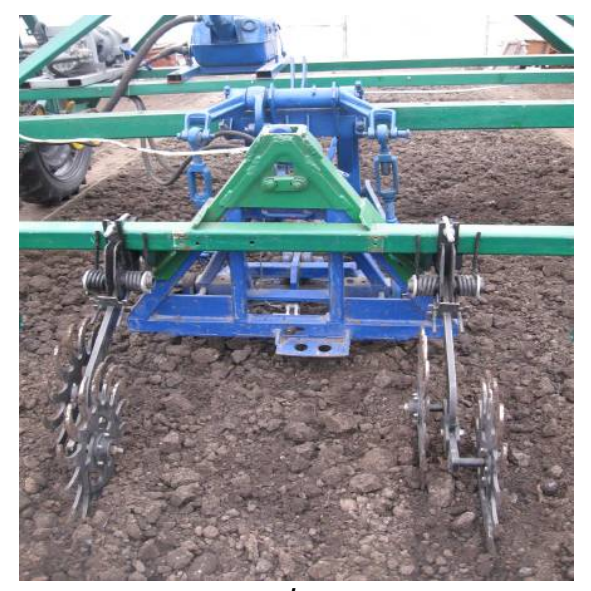

$b$

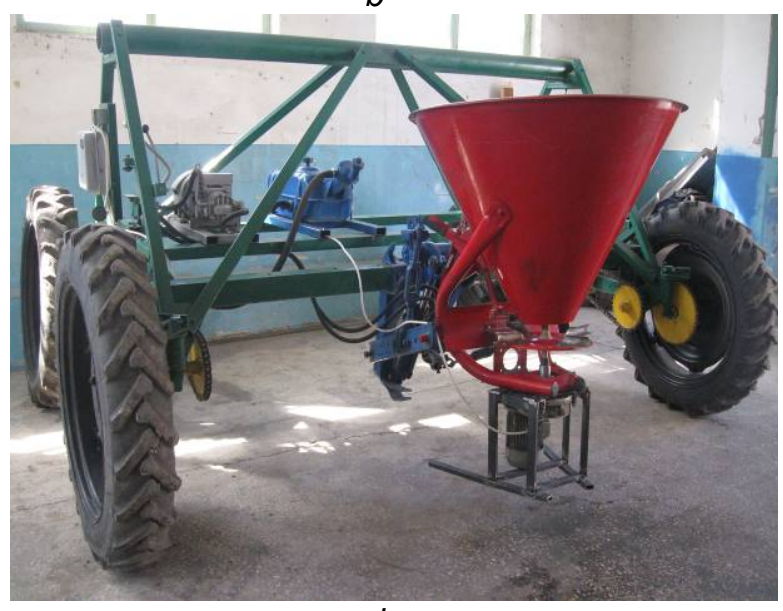

d

Fig. 2. Bridge agricultural unit as part of agricultural machinery during the research: a) tooth harrows (type BZSS-1,0) b - rotary harrow; $c$-S-shaped scarifier; $d$ - electrified mineral fertilizer spreader

Profiling of unevenness of the soil track of the constant tramline and agrophone was recorded by specially produced profilers using a PC (Fig. 3). The specified measuring complex contained a profilograph 1, mounted on rail 2, which is mounted on racks. A rheochord sensor 3 (SP-3A) was installed on the profilographs. When the profilograph 1 is moved on rail 2 , its wheel 4 reverses the unevenness of the background profile 5. With a change in the ordinate of the unevenness of the background 5 lever 6 of the profilograph 1 performs angular movements, changes the resistance of the rheochord sensor 3 . The signal from it (electric current) is fed to the analogue-to-digital converter 7 , which is powered by the battery 8 and is displayed on the PC 9 monitor. When profiling the unevenness of an agricultural phone, 
the operator moves the profiler evenly along the rail at a speed of about $0.5 \ldots 0.6 \mathrm{~m} / \mathrm{s}$ from one support stand to another.

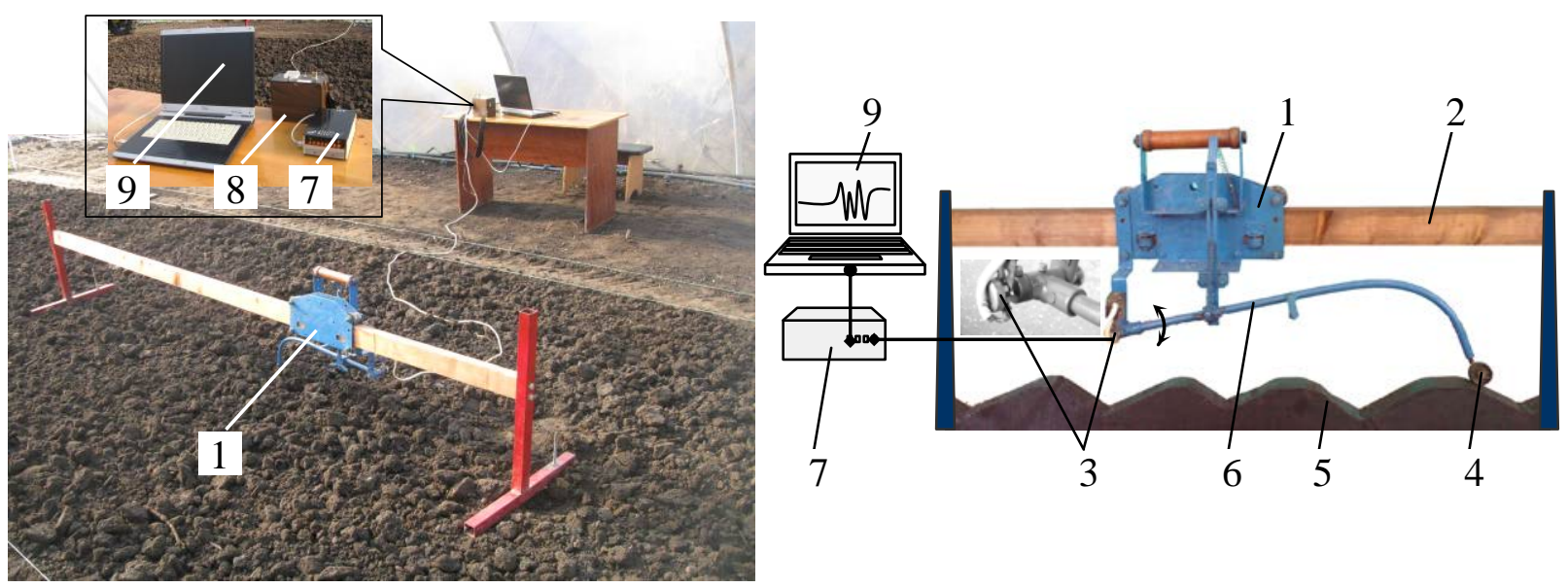

Fig. 3. Hardware and measuring complex for measuring the unevenness of the longitudinal profile of the agrophone

Taring of the profilograph (Fig. 3) was carried out on a level ground by placing bars of different thickness under its wheel. Thus the signal from resistance of rheochord sensor SP-3A was fixed with the help of analog-digital converter and PC [21].

The relative error of measuring the unevenness of the longitudinal profile of the agrophone with the specified hardware and measuring complex did not exceed $2.5 \%$.

To measure the traction resistance of agricultural units combined with agricultural tools, a special dynamometer coupling of CA type was used (Fig. 4), which was mounted on the tie rod of its attachment mechanism.

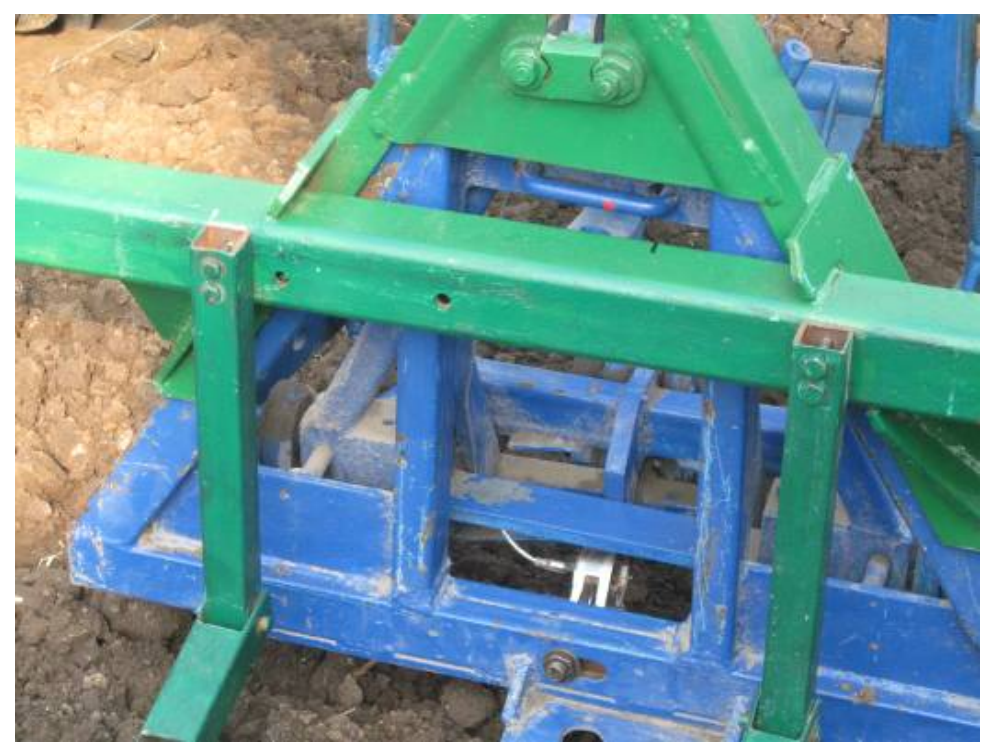

Fig. 4. Dynamometer coupling (CA type) with strain-gauge link of VISGOM construction, which is mounted on the attachment of the agricultural unit

As a measuring element of traction resistance of agricultural machinery tools used strain gauge link construction VISGOM with a measuring range of $0-10 \mathrm{kN}$ (fig. 4). Its tare was carried out on a special stand using a dynamometer DPU-2. The whole measuring range $(0-10 \mathrm{kN})$ was divided into 10 intervals. The value of loading and unloading ordinates in each point was recorded on the PC via analog-to-digital converter. The relative error of traction resistance measurements did not exceed $5 \%$.

Realization of fluctuations of investigated parameters received in the course of experimental researches in the form of the digitized data were transferred in software environment MathCad. The following statistical characteristics were calculated in it as: mean value, mean square deviation (standard), dispersion, coefficient of variation, error of sampling average, normalized correlation function, normalized spectral density. The error of direct measurement of parameters did not exceed $2 \%$. 
Soil moisture was determined by the standard thermostatic weight method. At carrying out of researches average value of humidity of soil in layer $0-12 \mathrm{~cm}$ was $24,4 \%$ and density was $1,23 \mathrm{~g} \cdot \mathrm{cm}^{-3}$.

The depth of processing during the research was measured with a depth gauge in 10 places on the diagonal of the research laboratory field area, which length was $50 \mathrm{~m}$. The speed mode of the bridge unit operation was as follows 3,3-4,4 km.(hour) $)^{-1}$.

Research results and their discussion. The analysis of the received experimental data showed that the profile of a constant technological track is essentially smoothed in comparison with a profile of the processed agrophone. Thus, if the mean square deviation of the profile of the treated agrophone was \pm $(1.32-1.44) \mathrm{cm}$, then for the track profile this figure was $\pm 0.84 \mathrm{~cm}$, ie $1.6-1.8$ times less.

According to their internal structure, the inequalities of the profile of traces of a constant technological track are characterized by a function that contains, along with random components - harmonic, which are expressed by fading periodic oscillations of the normalized correlation function (Fig. 5). Its analysis has shown that the correlation connection length of roughness profiles ordinates of traces of a constant technological track makes about $0,18 \mathrm{~m}$ that corresponds to a step of ground hooks of tires of a bridge agricultural unit which value for the size of tires $9.5 \mathrm{R} 32$ is equal to $0,175 \mathrm{~m}$.

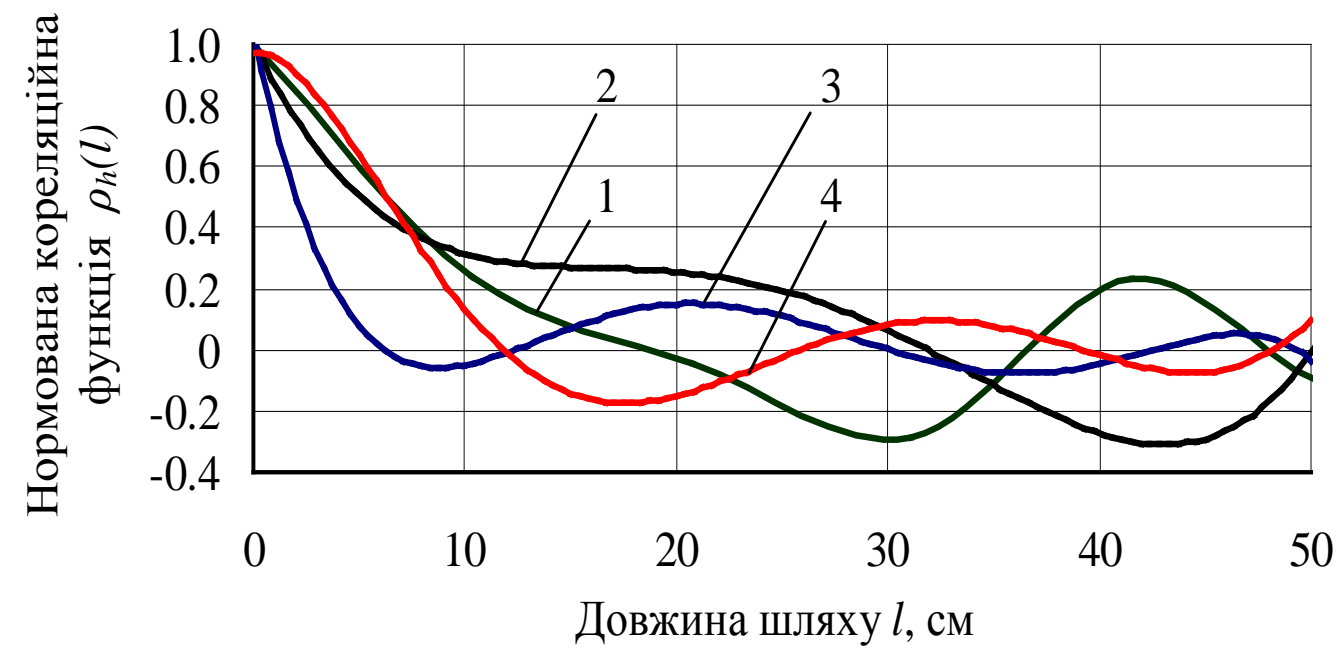

Fig. 5. Normalized correlation functions $\rho_{h}(l)$ of the profiles of background irregularities from

the path length $l: 1$ - traces of a constant technological track; 2 -agrophone after the passage of the tooth harrow; 3 - agrophone after the passage of the S-shaped spring ripper; 4 -agrophone after the passage of the rotary harrow

The graphs of the normalized correlation function (Fig. 5) have a similar character in their structure. The oscillations of the inequalities of the longitudinal profile of the processed agrophone, but differ in energy. Thus, their length of the correlation link is slightly different from the profile of unevenness traces of a constant tramline. And it depends on the type of technological operation on the cultivation of the soil with a bridge agricultural unit. For example, after the treatment of the agrotechnical zone of the field with a tooth harrow, this index is higher than for the unevenness of the traces of a constant tramline and equals $0.34 \mathrm{~m}$. And after the treatment with the rotary harrow and S-spring ripper, on the contrary, it is less and is $0,12 \mathrm{~m}$ and $0,08 \mathrm{~m}$ respectively. The obtained characteristics of the roughness of the treated agrophone in general correspond to the characteristics of the roughness of the fields prepared for sowing of agricultural crops.

The spectrum of frequencies, which make up a random function of the unevenness profile of the traces of a constant technological track, determines the normalized spectral density of their ordinates (Fig. 6). From its analysis it follows that the cutting frequency for this process is about $0.3 \mathrm{~cm}^{-1}$. The major part of the oscillation dispersions of the unevenness profile of tramline tracks is concentrated in the frequency range of $0 \ldots 0.3 \mathrm{~cm}^{-1}$. The average square deviation of the ordinates of the specified irregularities is consistent with the height of agricultural unit wheels ground hooks, the value of which for tire size $9.5 \mathrm{R} 32$ is equal to $0.03 \mathrm{~m}$. 


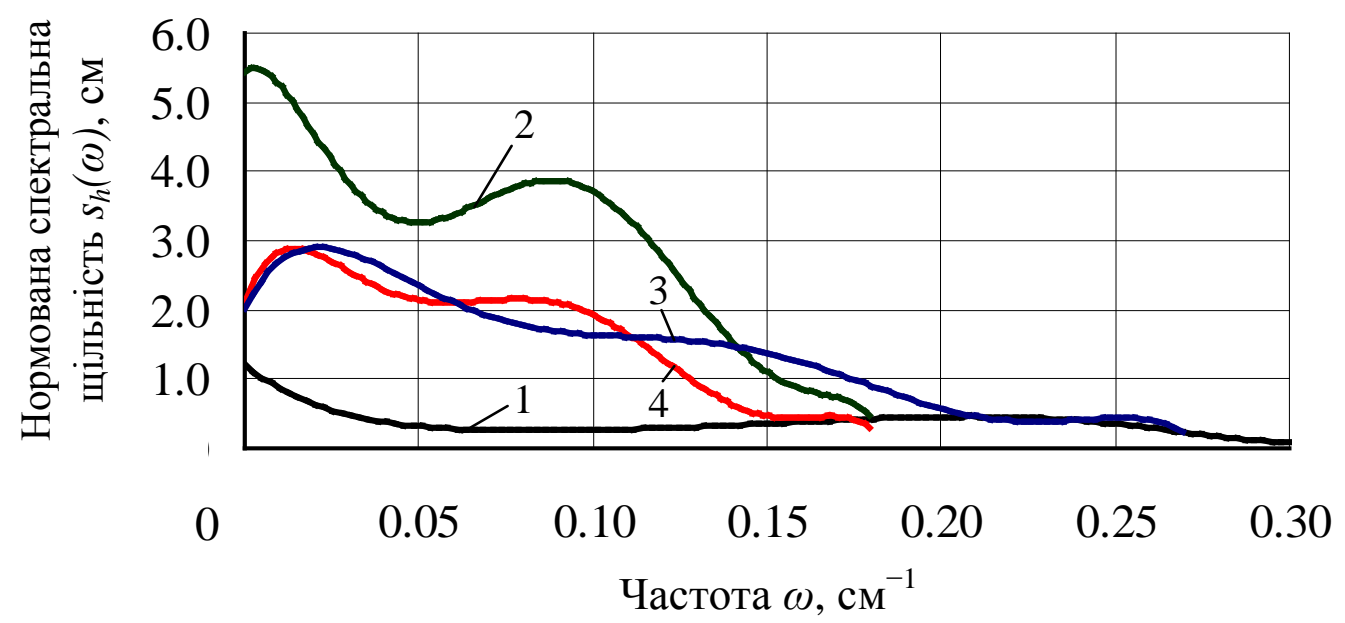

Fig. 6. Normalized spectral densities $S_{h}(\omega)$ profiles of background irregularities from

frequency $\omega: 1$ - traces of a constant technological track; 2 - agrophone after the passage of the tooth harrow; 3 - agrophone after the passage of the S-shaped spring ripper; 4 - agrophone after the passage of the rotary harrow

The presented above analysis of the profile roughness characteristics of the traces of a constant technological track, on which the bridge agricultural unit is moving many times (Fig. 5 and Fig. 6), indicates that the generator of the formation of these irregularities is the generator parameters of the tire ground hooks of its wheels.

In contrast to tires formed by the wheels of the bridge agricultural unit, the profile irregularities of the traces of a constant technological track of the treated agrophone have a higher frequency character (Fig. 6). From the analysis of the normalized spectral density of the unevenness frequency distribution of the treated agrophone it is established that the cut frequency for these processes is $0,18 \mathrm{~cm}^{-1}$. The major part of dispersions of oscillations of roughness of the treated agrophone is concentrated in the frequency range of $0-0.18 \mathrm{~cm}^{-1}$.

Fluctuations of traction resistance of agricultural implements at the operation of aggregates on the basis of bridge agricultural unit represent a random function, in which there are no harmonic components (Fig. 7).

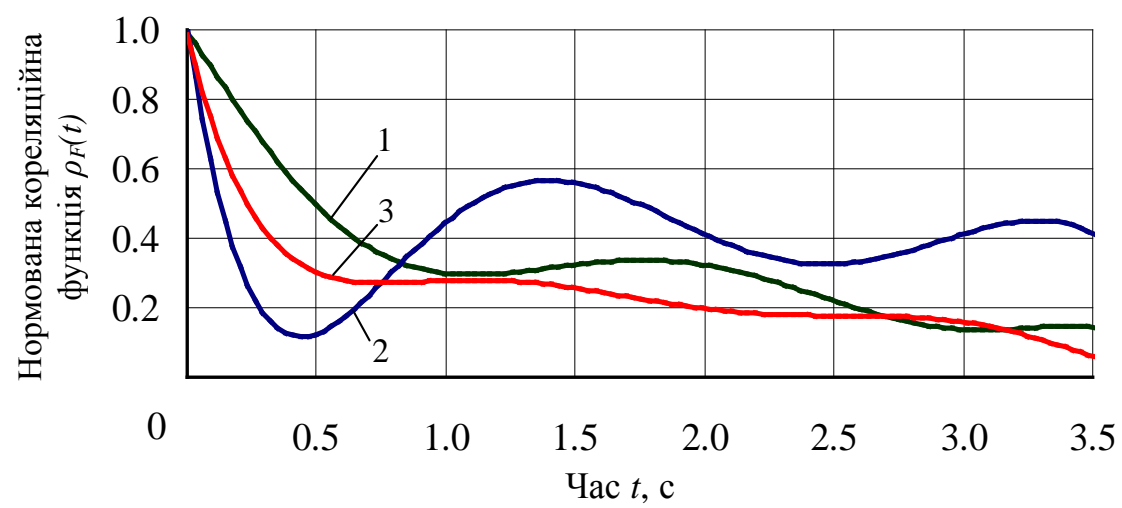

Fig. 7. Normalized correlation functions $\rho_{F}(t)$ of the fluctuations of traction resistance of agricultural implements from time to time $t$ for: 1 -toothed harrow; 2 - $S$-shaped spring ripper;

$$
3 \text { - rotary harrow }
$$

From the analysis of experimentally obtained normalized correlation functions (Fig. 7) of oscillations of traction resistance of agricultural implements, it follows that the degree of randomness of the process in the S-shaped spring ripper and rotary harrow is significantly higher. Because the values of their normalized correlation functions $\rho_{F}(t)$ rapidly decrease with increasing time $t$. This indicates a smaller dependence of their traction resistance on the process time.

The main spectrum of variances of oscillations of traction resistance of agricultural implements is concentrated in the frequency range $0-8 \mathrm{~s}^{-1}$ (fig. 8). From the analysis of the distribution of normalized 
spectral densities of traction resistance oscillations of the studied agricultural units it follows that the nature of the processes under consideration is almost the same.

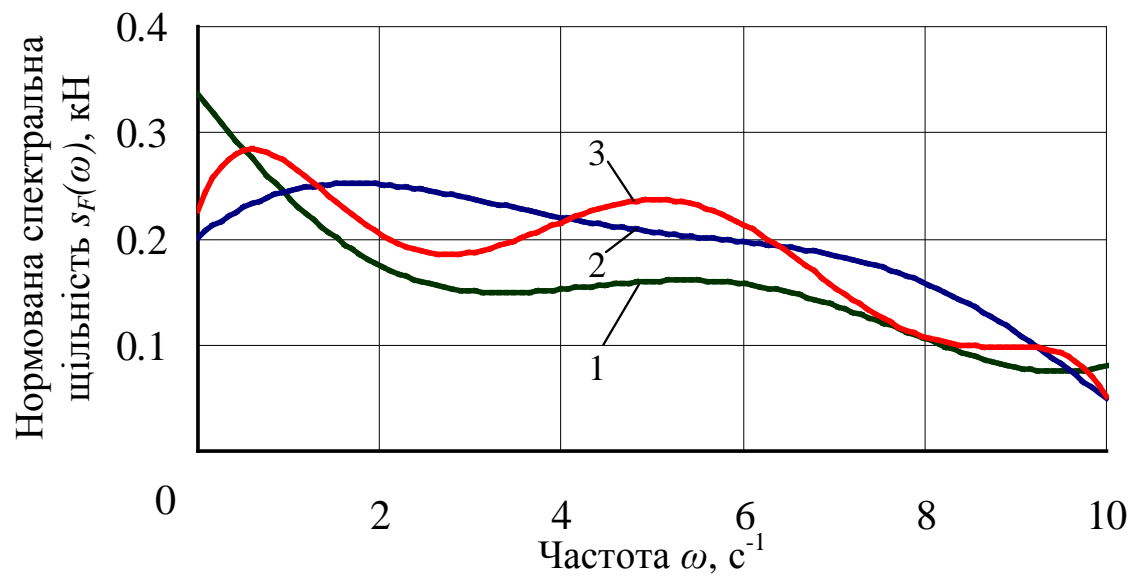

Fig. 8. Normalized spectral densities $S_{F}(\omega)$ oscillations of traction resistance of agricultural implements from frequency $\omega$ for: 1 - toothed harrow; 2 - S-shaped spring ripper; 3 -rotary harrow

In terms of its energy, the dispersion of oscillations of traction resistance of the studied agricultural units is approximately the same and is $0.022-0.033 \mathrm{kN}^{2}$, and the standard deviation is $0.142-0.163 \mathrm{kN}$. For three toothed harrows in the aggregate based on the bridge agricultural unit, the coefficient of variation of traction resistance was $9.76 \%$ with an average value of $1.71 \mathrm{kN}$. The obtained result is a good sign that indicates high stability (low variability) of the process of tillage with the studied tools.

The main productivity of these tillage units on the basis of the bridge agricultural unit was approximately the same and was equal to $1.08 \mathrm{ha} \cdot(\mathrm{h})^{-1}$. The specific energy consumption was $1.66 \mathrm{~kW}$ ra (ha) $)^{-1}$. While for similar traditional machine-tractor units with the same width of capture they make 2,77 $\mathrm{kW} \cdot(\mathrm{ha})^{-1}$. Therefore, the specific energy consumption per 1 ha of arable land with new units based on the bridge agricultural unit is $40 \%$ lower.

Indicators of the quality of tillage with a toothed harrow, S-shaped spring ripper and rotary harrow in units based on bridge agricultural equipment met the agricultural requirements related to these technological operations [22]. In particular, the deviation of the actual depth of tillage from the specified did not exceed $\pm 1 \mathrm{~cm}$, and the height of the ridges on the treated agricultural background was not more than $2 \mathrm{~cm}$.

According to the results of experimental studies of soil cultivating agricultural aggregates on the basis of bridge agricultural unit proved their high adaptability to work in the system of track farming. The quality of tillage with tooth harrow, S-spring ripper and rotary harrow is within the limits of arable farming.

The character of roughness fluctuations of cultivated agrophone profiles by soil tillage units on the basis of bridge agricultural unit is smoother. This is a consequence of the fact that the movement of specialized agricultural unit is carried out on the compacted traces of a constant tramline, the roughness profile of which has a lower frequency character. In the process of research it was established that the generator of the formation of ridges of irregularities in the traces of a constant technological track are the parameters of the ground hooks of tires of agricultural unit wheels.

Experimental studies have shown that the operation of soil tillage units based on bridge agricultural unit also displays well on the character of their traction resistance fluctuations. Normalized correlation functions of these oscillations do not contain harmonic components. The coefficient of variation of resistance vibrations of agricultural implements on a hook of agricultural unit is no more than $10 \%$. It testifies to high stability (low variability) of processes of mechanical processing of soil by a bridge agricultural unit which moves on the traces of a constant technological track that positively affects stability of its movement.

For a bridge agricultural vehicle, the track width of which is equal to $K=3,5 \mathrm{~m}$, it is enough to have an angular velocity of rotation of the centrifugal working body of the electrified spreader of mineral fertilizers JarMet, equal to $=15.5 \mathrm{rad} \cdot(\mathrm{s})^{-1}$. Power consumption for its drive is $0.35 \mathrm{~kW}$. If we hypothetically increase the track width of the bridge agricultural unit to $6 \mathrm{~m}$, the required angular velocity of the centrifugal working body for spreading fertilizers increases exponentially to $318.2 \mathrm{rad} \cdot(\mathrm{s})^{-1}$. Naturally, such an increase in the angular velocity of rotation of the centrifugal body requires a corresponding increase in power consumption for its drive.

According to the results of the conducted tests of the bridge agricultural unit we have offered a number of schemes of new agricultural implements adapted for aggregation with similar bridge agricultural unit 
and ways of performing agrotechnological operations for which patents for inventions and utility models of Ukraine have been obtained (№100657, №119800, №124946, №126787, №132889, №133491, №134274, №134275, etc.).

\section{Conclusions}

As a result of the conducted experimental researches it is established that the main generator of formation of roughnesses of a longitudinal profile of soil traces of a constant technological track are parameters of soil hooks of tires of wheels of the bridge agricultural unit. Thus, under the conditions of agricultural unit testing, the major part of the dispersions of oscillations of the longitudinal profile of the tramline tracks is concentrated in the frequency range of $0 \ldots 0,3 \mathrm{~cm}^{-1}$, which is consistent with the height of the ground hooks of its tires 9.5R32, which is equal to $0.03 \mathrm{~m}$. This is confirmed by the fact that the length of the correlation connection of the ordinates of irregularities in the profile of the traces of a constant tramline in the conditions of agricultural unit testing is about $0.18 \mathrm{~m}$, which corresponds to the step of its tire ground hooks, equal to $0.175 \mathrm{~m}$.

The character of the oscillations of the roughness profiles of the treated agrophone by the bridge agricultural unit with the agricultural tools (S-spring ripper and rotary harrow) is smoother, which is a consequence of the movement of the agricultural unit on the compacted traces of a constant tramline, the roughness profile of which has a lower frequency character. This is evidenced by a smaller average square deviation of the amplitudes of irregularities of the specified profiles (by 1.6-1.8 times). The main part of the oscillation dispersions of the roughness of the treated agrophone is concentrated in the frequency range of 0-0.18 $\mathrm{cm}^{-1}$, and the length of their correlation is about 2 times longer than the longitudinal profile of the constant technological track.

The coefficient of variation of traction resistance of agricultural implements in the units based on the bridge agricultural unit is not more than $10 \%$, the main spectrum of their dispersions is concentrated in the frequency range 0-8 $s^{-1}$, and the normalized correlation functions of these oscillations do not contain harmonic components. This indicates a high stability (low variability) of tillage processes by a bridge agricultural unit, which moves in the footsteps of a constant technological track, which has a positive effect on its stable movement.

Power costs for the drive of a centrifugal working body for spreading fertilizers on the basis of a bridge agricultural unit are relatively small and amount to $0.35 \mathrm{~kW}$.

The quality of tillage with units based on bridge agricultural equipment is approximately the same as that of similar traditional machine-tractor units. But the specific energy consumption per 1 hectare of arable land with new units is $40 \%$ lower.

\section{References}

1. Chamen, T. (2015). Controlled traffic farming - from world wide research to adoption in Europe and its future prospects. Acta Technologica Agriculturae, 3, 64-73.

2. Onal, I. (2012). Controlled Traffic farming and Wide Span Tractors. Journal of Agricultural Machinery Science, 8(4), 353-364.

3. Bulgakov, V., Adamchuk, V., Kuvachov, V. et al. (2017). Research of possibilities for efficient use of wide span tractor (vehicle) for controlled traffic farming. (24 - 26 may 2017, Jelgava, Latvia). Engineering for rural development: Proceedings 16 International Scientific Conference, 16, 281287.

4. Pedersen, H.H., Oudshoorn, F.W., McPhee, J.E. et al. (2016). Wide span - Re-mechanising vegetable production. Acta Horticulturae, 1130, 551-557.

5. Bulgakov, V., Melnik, V., Kuvachov, V. et al. (2018). Theoretical study on linkage unit of wide span tractor. Proceedings 29th DAAAM International symposium "Intelligent manufacturing and automation» (24-27th October 2018, Zadar, Croatia). DAAAM International. Vienna, Austria, P. 0180-0189.

6. Derkach, O.D., Makarenko, D.O., Litvintseva, Yu.O. et al. (2018). Upgrading of machines for surface tillage (for cultivators). Collected Scientific Papers «Geo-Technical Mechanics», 138, 260270.

7. Mitkov, V., Kuvachov, V., Ihnatiev, Ye. et al. (2016). New approach to the choice of way of mechanical processing of soil in the south of Ukraine. International Scientific Journal «Mechanization in agriculture». Is. 1, 29-31.

8. Uleksin, V.A. (2008). Mostovoe zemledelie [Bridge farming]. A monograph. Dnepropetrovsk: Thresholds. [In Russian].

9. Kuvachov, V.P. (2019). Eksperymentalni vyprobuvannia ahromostovoho boronuvalnoho ahrehatu [Experimental tests of agro-bridge harrowing unit]. Works of TSATU, 19(4), 223-233.

10. Nadykto, V.T., Hoichuk, A.F., Kiurchev, V.M. (2006). Perspektyvy vprovadzhennia koliinoi systemy zemlerobstva na Ukraini [Prospects for the implementation of the track system of agriculture in Ukraine]. Scientific Bulletin of NAU, 92, 38-43.

11. Pedersen, H.H., Oudshoorn, F.W., McPhee, J.E. (2016). Wide span - re-mechanising vegetable production. XXIX International horticultural congress on horticulture: sustaining lives, livelihoods and landscapes: international symposia on the physiology of perennial fruit crops and production 
systems and mechanisation, precision horticulture and robotics Book Series: Acta Horticulturae, $1130,551-557$.

12. Bulgakov, V., Kuvachov, V., Olt, J. (2019). Theoretical study on power performance of agricultural gantry systems. Proceedings 30th DAAAM International symposium «Intelligent manufacturing and automation» (23-26th October 2019, Zadar, Croatia). DAAAM International. Vienna, Austria, 01670175.

13. Transportnyi enerhetychnyi zasib [Vehicle energy]. Pat. for the invention 120299 Ukraine: A01B 49/00, A01B 49/04, A01B 63/16, A01B 63/22. № a 201710579; declared 01.11.2017; publ. 11/11/2019, Bull. № 21. [In Ukrainian].

14. Transportnyi enerhetychnyi zasib [Vehicle energy]. Pat. for the invention 120388 Ukraine: A01B 49/00, B60B 35/104. 2017 a 201710576; declared 01.11.2017; publ. 11/25/2019, Bull. № 22. [In Ukrainian].

15. Sposib realizatsii mostovoho zemlerobstva [The method of implementation of bridge farming]. US Pat. on cor. mod. 84884 Ukraine: IPC A01B49/00. № u 201302692; declared 04.03.2013; publ. 11.11.2013, Bull. № 21. [In Ukrainian].

16. Mostovyi zasib dlia silskohospodarskykh robit [Bridge tool for agricultural work]. US Pat. on cor. mod. 84883 Ukraine: IPC A01B49/00. № u 201302688; declared 04.03.2013; publ. 11.11.2013, Bull. № 21. [In Ukrainian].

17. Mostovyi zasib dlia silskohospodarskykh robit [Bridge tool for agricultural work]. US Pat. on cor. mod. 93888 Ukraine: IPC A01B 49/00. № u 201403094; declared 27.03.2014; publ. 10/27/2014, Bull. № 20. [In Ukrainian].

18. Gmurman, V.E. (2016). Teoriya veroyatnostey i matematicheskaya statistika: uchebnik dlya SPO [Probability theory and mathematical statistics]. A textbook for open source software. Moscow: Yurayt Publishing House. [In Russian].

19. Kuvachov, V.P., Mitkov, V.B., Ihnatiev, Ye.I. et al. (2020). Metodolohiia perevirky matematychnykh modelei funktsionuvannia ahromostovykh system na adekvatnist [Methodology of checking the mathematical models of functioning of agro-bridge systems for adequacy]. Scientific Bulletin of TSATU, 10(1). [In Ukrainian].

20. Borona Nadykty-Aiubova dlia obrobitku gruntu pid par [Nadykta-Ayubov harrow for tillage under steam]. pat. 88940 Ukraine. № u201311396; declared 26.09.2013; publ. 10.04.2014, Bull. № 7 .

21. Kuvachov, V.P., Kiurchev, V.M., Nadykto, V.T. (2008). Metodyka ta rezultaty otsinky nerivnostei profiliu gruntovo-dorozhnykh foniv za dopomohoiu EOM [Methods and results of estimating the irregularities of the profile of soil and road backgrounds using a computer]. Works of TSATU, 8(6), 28-34. [In Ukrainian].

22. Ormaji, K.S. (1991). Kontrol kachestva polevykh rabot [Quality control of field work]. Moscow: Rosagroprom. [In Russian]. 